\title{
PSYCHE
}

\section{BIOLOGICAL NOTES ON THE COLORADO POTATO BEETLE, LEP- TINOTARSA DECEMLINEATA (SAY), WITH TECHNICAL DESCRIPTION OF ITS STAGES.}

\author{
By A. A. GIRAUlt AND A. H. ROSENFELd.
}

DURING the spring and summer of 1906 it became convenient to make a brief study of this insect, more in reference to the biological aspects of its life than otherwise. There seem to be but few records in our literature concerning the duration of its different stages, especially in the southern United States. The following facts are therefore presented for publication without further comment. The observations were made at Myrtle, Ga., about 32 degrees, 30 minutes north latitude.

\section{The EGG.}

Description.- Length, 1.70-1.80 mm.; $1.75 \mathrm{~mm}$., average. Width, $0.80 \mathrm{~mm}$., average, greatest diameter. Body uniformly bright orange, opaque, the ends paler, yellowish, and translucent. Shape elongate oval, the outline slightly irregular, and the caudal end or base, and the apex, regularly rounded. Surface simple, glabrous, apparently very minutely punctulate, with a moist appearance. Micropyle simple, inconspicuous. Chorion soft, easily crushed, and more or less elastic. To the naked eye, conspicuous.

Deposited erect, in small irregular masses of 20 or 30, more or less, generally on the under surfaces of the leaves. Caudal end held by a small orange pad of adhesive matter. (From many specimens.)

External Development.- The egg shows no sign of embryonic development externally until about the twelfth hour before hatching, when the perfect embryo is visible, together with all of the markings of the first larval instar at eclosion. The ocellar spots are in a rectangle at the anterior end of the egg, and the larger lateral tubercle areae and spiracles are distinctly visible on the sides. The setae are visible as blackish streaks along the sides in nearly regular rows. The disposition of the appendages is not distinct. The markings are more distinct as the egg approaches the time of hatching.

Duration of Stage. - In all the period of incubation for five hundred eggs has been determined to the hour, as accurately as possible under laboratory conditions. 
Table I. Length of Period of Incubation at Different Dates, Myrtle, Ga. 1906.

\begin{tabular}{|c|c|c|c|c|c|c|c|c|c|c|}
\hline $\begin{array}{l}\text { Lot. } \\
\text { no. }\end{array}$ & $\begin{array}{l}\text { No. } \\
\text { eggs. }\end{array}$ & & Time & Deposited. & & Time & Hatched. & $\begin{array}{l}\text { Length } \\
\text { Days }\end{array}$ & $\begin{array}{l}\text { of Stage } \\
\text { Hours. }\end{array}$ & $\begin{array}{c}\text { Effective Temp } \\
\text { Degrees F. }\end{array}$ \\
\hline 1. & 40. & May & 21 , & $3: 30 \mathrm{~A}$. & May & 26 , & $12: 30 \mathrm{P}$. & 5 & 9. & $33 .^{\circ}$ \\
\hline 2. & 53. & & 22 , & 5:00 A. & & 27 & 5:00 P. & 5 & 12. & 32.67. \\
\hline 3. & 30. & & 22 , & $1: 30 \mathrm{P}$. & & 28 & $3: 30 \mathrm{~A}$. & 5 & 14. & 33.50 . \\
\hline 4. & 41. & & 23 , & $8: 45 \mathrm{P}$. & & 29 , & 11:00 A. & 5 & $14 \frac{1}{4}$. & 33.21 . \\
\hline 5. & 9. & & 24 , & $1: 45 \mathrm{~A}$. & & 29 , & 11:00 A. & 5 & $9 \frac{1}{4}$ & 33.75 . \\
\hline 6. & 40. & & 24 , & 9:00 P. & & 30 & $7: 30 \mathrm{~A}$. & 5 & $10 \frac{1}{2}$ & 33.61 . \\
\hline 7. & 33. & & 25 , & 1:00 P. & & 30 & $10: 45 \mathrm{P}$. & 5 & $9 \frac{3}{4}$ & 33.46 . \\
\hline 8. & 38. & & 26 , & $2: 45 \mathrm{P}$ & & 31 , & 8:00 P. & 5 & $5 \frac{1}{4}$. & 33.79 . \\
\hline 9. & 41. & & 27 , & 12:00 M. & June & 1 & $3: 30 \mathrm{P}$. & 5 & $3 \frac{1}{2}$. & 34.53 . \\
\hline 10. & 23. & & 28 , & $12: 30 \mathrm{P}$. & & 2 , & $1: 45 \mathrm{P}$. & 5 & $1 \frac{1}{4}$. & 35.95 . \\
\hline 11. & 39 . & & & $3: 25 \mathrm{P}$. & & & 10:10 P. & 4 & $6 \frac{1}{2}$ & 35.44 . \\
\hline 12. & 23. & & 30 , & $11: 45 \mathrm{~A}$. & & 3 , & $8: 45 \mathrm{P}$. & 4 & 9. & 37.64 . \\
\hline 13. & 35. & & 31 , & 1:00 P. & & 4 & 3:00 P. & 4 & 2. & 38.89 . \\
\hline 14. & 20. & June & 2 , & 3:00 P. & & 6 & $8: 45$ P. & 4 & $5 \frac{3}{4}$ & 40.10 . \\
\hline 15. & 14. & & 3 , & 4:45 A. & & 7 & 8:00 A. & 4 & $3 \frac{1}{4}$ & 40. \\
\hline 16. & 21. & & 3 , & 5:00 P. & & 8 , & 8:00 A. & 4 & 15. & 40.50 . \\
\hline yer & & & & & & & & 4 & 23 & $35.62^{\circ}$ \\
\hline
\end{tabular}

Glancing down the column, it is seen that even during the short period of two weeks, there is a gradual decrease of the period of incubation, and a correspondingly gradual increase of the sums of effective temperatures. The exceptions are due to short cool spells.

The average of 35.62 degrees $\mathrm{F}$. agrees well with most of the average sums of effective temperatures shown in the table.

Period of Hatching. The period of hatching of an egg-mass varies somewhat, but averages about three hours under usual spring conditions. The eggs in any single mass hatch almost simultaneously.

\section{Number Deposited.}

The data obtained on this point consists of but a single record, obtained by confining a pair of adults with food. These were captured in copula at 5 P. M. May 20, 1906, and then confined. The female deposited eggs as follows:- 
Table II. Number of eggs deposited by a single female in confinement.

\begin{tabular}{rrr} 
Date. & Mass Number. & No. Eggs. \\
May 21. & 1. & 40. \\
22. & 2. & 53. \\
22. & 3. & 30. \\
23. & 4. & 16. \\
23. & 5. & 41. \\
24. & 6. & 9. \\
24. & 7. & 40. \\
25. & 8. & 33. \\
26. & 9. & 38. \\
27. & 10. & 41. \\
28. & 11. & 23. \\
29. & 12. & 39. \\
30. & 13. & 23. \\
31. & 14. & 35. \\
June & 15. & 20. \\
3. & 16. & 14. \\
3. & 17. & 21. \\
5. & 18. & 9. \\
\hline & - & 525
\end{tabular}

Period of Oviposition. From the table just given, it is seen that, in this case, the period of oviposition lasted for over fifteen days. However, this female was probably some days old when captured, so that the record is not complete, and a much longer period than this may be expected.

\section{The Larva.}

Description of the Instars. The larva or grub of the Colorado Potato Beetle is of the usual cruciform type, with a large, fleshy, subovate, prehensile body, antenniferous and hexapod, and bearing a terminal proleg. It is an external and voracious feeder, and grows rapidly, but is sluggish in habit.

Immediately following exclusion from the egg, the larva is entirely light orange (unicolored), with the following exceptions,-- ocellar spots reddish, tubercle areas blackish, minute, inconspicuous, excepting three large areas, one on the dorsolateral aspect of the last two thoracic and the first abdominal segments; tibiae and tarsi paler, translucent; apical end of the antennae and the tips of the tarsi dusky; cervical and anal shields concolorous. Dorsal aspect, body uniformly orange yellow, 
paler at anal end, the three large tubercle areas above mentioned conspicuous, followed by the minute and much less conspicuous spiracles. Mandibles reddish brown; anal proleg large, paler. After several hours the larva becomes normally colored for the first instar.

\section{Instar I. Length after exclusion - $\quad 1.50 \mathrm{~mm}$. , avg. \\ Length before ecdysis - $2.60 \mathrm{~mm}$., avg. \\ Width of head - $\quad 0.65 \mathrm{~mm}$., avg.}

Body fleshy, from cephalic aspect tubular, from dorsal aspect gourd-shaped; dorsal plane at head and thorax, inclined, at abdomen greatly convexed; lateral aspect, ventral plane straight, or slightly concaved near caudal end; with nine abdominal segments, the anal segment bearing a pair of prehensile prolegs. Body thickest at 4th abdominal segment, narrowed at head and thorax, and tapering caudad. Stigmata distinct, circular, and similar on thorax and abdomen; black.

Head peltate, narrower than following segment, flat, directed ventrad, glabrous black, subhirsute, rather soft, though chitinous. Ocelli six, 4 arranged so as to form a square, the remaining two in a line on the lateral aspect of the head; the lateral two ocelli, of the four in a square, are ocellate with orange; all slightly protuberant, and black. Antennae 3-jointed, the first joint paler, joints 1 and 2 subequal, broader than joint 3 ; the apical joint conical, ending in three or four stiff, sensory setae, and paler distally (dorsal aspect); in reality (lateral aspect) black, nearly uniform in width, the distal joint apparently 2-branched, its dorsal branch much the larger, cylindrical and truncate, and the ventral branch slender, conical, and spine-like, in reality, a spinous prolongation of the ventro-cephalic angle of joint 3 (the appendix).

Mandibles short and broad, at base about two-thirds as wide as long, pale yellowish, fuscous at tips, subrectangular, outer margin slightly curved and convex, the inner margin shorter and irregular; with four strong acute serrations, of which the first three are about equal in size, the second, however, about one-third longer, the fourth or inner one-half shorter and blunt. Maxillary palpi 3-jointed, longer than the antennae; labial palpi 2-jointed; both apparently with an additional basal joint, evidently a portion of the stipes; both paler at tip. Labrum broad, notched at the median line. Maxillary and labial palpi both bear sensory setae.

Thorax cylindrical, prothorax largest, its shield covering nearly the whole of the dorsum, black and divided by a thin median line concolorous with body; tubercles more abundant on the shield. Thoracic segments corrugated, the sclerites inconspicuous.

Legs black, the articulations paler, 5-jointed (usual leg joints), the coxa broad, tibia and femur subequal in length, the former more slender; from dorsal aspect (natural position), most of the tibia and all of the tarsus visible. Tarsi, 1-jointed, 
bearing, a single, large, sharp claw, which is pale and bent sharply ventrad, the empodium apparently simple. Legs with sparse, stiff, long hairs; ambulatorial and subscansorial.

Abdomen fleshy, abruptly convex above, slightly concave. below, widest at about the 4th segment; surface microscopically papillose, from naked eye smooth and shining. Cerci absent. Articulations indistinct. Scansorial.

Body marked as follows-Head, cervical and anal shields, legs, median line of abdomen, stigmata, and most of the tubercle areae, black; trochanters pale. The tubercle areae are arranged as follows:-

Segment I-As in instar II.

II-As in instar II; an additional flat round area, rotato-rugose, just above the large area, and in dorsal region, 2 transverse areae, at cephalic and caudal margins of the segment respectively.

III-Same as in instar II; with the additions as noted for segment II.

IV-Same as in instar II. Two additional areae in a longitudinal line just above each spiracle, coalesced, forming a crescent; in dorsal region, 4 areae, the first 2 coalesced, arranged in an irregular square, on each side of meson.

V-IX-Same; the two above the spiracle on segment 3, with an arm joining them. The 2 cephalic ones in dorsal region not coalesced; the cephalic one in that region minute, the next twice larger, and the 2 caudal ones subequal, at least 7 or 8 times larger than the cephalic one.

$\mathrm{X}$-The same. The 4 in dorsal region closer, the 2 cephalic ones nearly in a transverse line at cephalic margin of segment; the 2 caudal ones, included with the cephalic margin of the anal shield, which covers portions of this segment, caudad.

XI-Tubercles still closer together, those above, in the shield; areae smaller. Apparently the same.

Instar II. Length after exclusion - $2.80 \mathrm{~mm}$., avg.

Length before ecdysis - $5.3 \mathrm{~mm}$., avg.

Width of head - $\quad 1.09 \mathrm{~mm}$., avg.

Following the first ecdysis, the whole body is a bright crimson, the head and prothorax brighter, the ocelli and most of the tubercle areae black. Exuvium entire, black.

The same. Body more tubular (dorsal aspect); from lateral aspect, ventral surface nearly regularly concave, the dorsal surface convex, the convexity abruptly broken at segments 2 and 3, which are concave; from dorsal aspect, body narrower 
at thorax, widest at 2nd abdominal segment, and subacute at anal extremity; declivous at 5th or 6th abdominal segment.

Head the same, more rounded posteriorly, black, nearly as wide as the thorax, bearing scattered minute tubercles from each of which arise single, moderately long setae; head hispid, surface subscabrous. Ocelli inconspicuous; antennae the same, inserted below the center of the face, the first joint pale, the third joint pale at apex, the appendix pale; antennae retractile. Mandibles the same, relatively broader, darker, subtriangular, the outer margin subsinuate and more straight, the inner emarginate, the teeth stronger, the outer one slightly shorter, the inner or 4th more obtuse, nearly truncate. Maxillary palpi with basal joint pale. Clypeus broad and narrow.

Thorax narrower than in instar I, in proportion to body; the same. Legs the same, stouter, the claw fuscous.

Abdomen convex, oval, naked, ambulatorial, but with a single pair of prolegs situate at anal extremity; segmentation more or less distinct, ventral surface concave; ninth segment prehensile. Anus terminal. Cerci absent.

Body marked as follows-Head, cervical shield, some of the tubercle areae, legs, and anal shield, black, the latter rather dusky; cervical shield paler, subochreous near cephalic margin; remainder of the body ochreous. The prominent black tubercles and spiracles are arranged as follows:-

Segment I - The oval, dusky spiracle is on lateral aspect, contiguous to the base of the leg.

II -2 areae on lateral aspect in a line cephalo-caudad, the more dorsal one larger; 4 on the dorsum in a square; 2 linear areae on each side of the meson.

III - The same; the two lateral areae in a line ventro-dorsad, the dorsal one much larger.

IV-XI - Lateral aspect, two large rounded areae in a line ventro-dorsad, subequal, forming a double line of dots along the side of abdomen; the dorsal ones are spiracles. On segments IX, X, and $\mathrm{XI}$, paler, brownish, the dorsal areae much smaller (minute on XI and near anal shield), but more black.

Remaining areae very minute, but a longitudinal line on sides of ventum of abdomen are inclined to be conspicuous (segments IV-X). Anal shield quadrate, including segments XI and XII, forming a rectangle on each segment. A median line of black, fading caudad. 
Instar III. Length after exclusion $-5.45 \mathrm{~mm}$., avg.

Length before ecdysis $-8.50 \mathrm{~mm}$., avg.

Width of head $\quad-1.67 \mathrm{~mm}$., avg.

The same. Dorsal body more convex, the 2nd and 3rd thoracic segments inclined; widest at third abdominal segment.

Head relatively wider, at least five times wider than long, anterio-posteriorly, its greatest transverse diameter just caudad of the insertion of the antennae; sculptured into irregular polygons by fine lines. Ocelli black, convex. Antennae, maxillary and labial palpi, the same. Mandibles stronger, more broad and triangular, the teeth forming a broad apex, rather than a fourth side; the 2nd tooth by far the largest, the 4th or mesal one truncate. Clypeus with three equal tubercles in an oblique (cephalo-laterad) transverse line, on each side of the meson, each bearing a single seta. Mandibles black along their outer edges.

Prothoracic segment much the largest, the shield peltate, emarginate along caudal margin; second segment at times partially concealed. Stigmata of prothorax round, large black areae, more caudad. Legs the same; tibia rectangular, slightly longer than the femur, and at least one-third narrower; claw and empodium orange yellow; coxa large and conical; trochanter subtriangular.

Abdomen the same, more convexed, prehensile, thicker laterad than dorso-ventrad; segmentation more distinct, surface minutely papillose, from naked eye, smooth.

Body markings the same, more distinct. Cervical shield bordered with ochreous at cephalic margin, involving also portions of the lateral margins, anteriorly; portions of the legs ochreous. Stigmata in large, oval, glabrous black areae, simulating coalesced tubercle areae, as in instar II. Tubercle areae the same, the anterior pair on dorsum of 2nd and 3rd thoracic segments subobsolete; the lateral areae on abdomen subequal.

$$
\begin{aligned}
& \text { Instar IV. Length after exclusion }-9.00 \mathrm{~mm} \text {., avg. } \\
& \text { Length before ecdysis }-15.00 \mathrm{~mm} \text {., avg. } \\
& \text { Width of head }-2.50 \mathrm{~mm} \text {., avg. }
\end{aligned}
$$

The same. Prothoracic segment conspicuous, much wider than segments 2 and 3 , and often completely concealing segment 2. Body widest at segments 3 and 4 of abdomen; more elongate, with the ventral surfaces more straight or flat, and with the outlines from dorsal aspect sinuate. Convexity of dorsal surfaces less apparent.

Head more conspicuous, more round, nearly one-half narrower than the first thoracic segment, ovalin actual outline; its greatest transverse diameter passes between the caudal and the intermediate groups of two of the ocelli; face engraved, sculpture of head slightly stronger. Ocelli and antennae the same, black. Mandibles fuscous, darker at the teeth, at base nearly as wide as long; teeth stouter and less acute. 
Thorax less inclined, the prothoracic segment from dorsal aspect conspicuous, wider than the two following segments, the shield covering most or whole of the dorsal surface, and overlapping much of the mesothoracic segment, and lateral aspect of segment 1, twice wider than long and not emarginate at is caudal margin. Legs the same, the coxae of the second and third pairs not as large as those of the foreleg. Body of claw straight.

Abdomen the same, less convex dorsad, and more flat ventrad, very prehensile; more corrugate.

Body markings the same. Median line of head and thorax ochreous, that of abdomen, dusky. Face ochreous, or mostly so, and also most of the occipital region of the head. Cervical shield concolorous with body, bordered caudad with black, its caudal edge ochreous, Stigmatal areae larger, conspicuous, glabrous black, irregular, equal or subequal on first 4 abdominal segments, slightly smaller on the fifth, one-third smaller on the sixth, two-thirds smaller on the seventh, and on the eighth abdominal segment minute, partially concealed in the incision of segment 7 . Anal shield black. Proleg orange. Coxae and trochanters concolorous with body, as is also the mentum.

First pairs of tubercle areae on dorsum of meso- and metathoracic segments inconspicuous, sometimes apparently obsolete; the dorsal one on lateral aspect of the same segments more prominent, conical. The line of small areae on ventrolateral aspect of abdomen less distinct. Shields of legs black. There are three small round tubercle areae also visible on the caudal margin of the 7 th abdominal segment, on each side of the median line, just cephalad of the anal shield; they are flat, rotato-rugose. They are also present on the cephalic margin of that segment, observed when that margin is visible.

Just previous to pupation the body of the larva becomes contracted, and the prothoracic segment swollen; the body is also more convex, and the legs are applied close to the ventum. The colors fade slightly. The larva is then perfectly motionless in its cell in the ground.

Described from a lot of 10 larvae reared under similar conditions.

Duration of larval instars. Three separate lots were reared with this object in view, comprising a total number of nineteen larvae. Two lots were run together in field and laboratory and practically agreed in the duration of the different instars. The third lot (lot No. 2 in the table), was not supplied with soil after the third ecdysis, and pupated nakedly, apparently after the normal period, thus giving the actual length of instar IV. It is interesting to note in this connection that the time of ecdysis for lots of larvae of the same age was nearly simultaneous, all molting within a period of three or four hours. 
Table III. Duration of larval instars.

\begin{tabular}{|c|c|c|c|c|c|c|c|}
\hline $\begin{array}{l}\text { Lot } \\
\text { No. }\end{array}$ & $\begin{array}{l}\text { No. } \\
\text { larvæ }\end{array}$ & $\begin{array}{l}\text { Date of } \\
\text { Hatching }\end{array}$ & $\begin{array}{l}\text { 1st Ecdysis } \\
\text { Instar I }\end{array}$ & $\begin{array}{l}\text { 2nd Ecdysis } \\
\text { Instar II }\end{array}$ & $\begin{array}{l}\text { 3rd Ecdysis } \\
\text { Instar III }\end{array}$ & $\begin{array}{c}\text { Entered Soil } \\
\text { Instar IV }\end{array}$ & Sums \\
\hline 11 & 5 & P.M., May 26 & $\begin{array}{l}\text { A.M., May } 29 \\
2 \frac{1}{2} \text { days }\end{array}$ & $\begin{array}{l}\text { P.M., May } 31 \\
2 \ddagger \text { days }\end{array}$ & $\begin{array}{l}\text { A.M., June } 2 \\
2 \frac{3}{4} \text { days }\end{array}$ & $\begin{array}{l}\text { P.M., June } 5 \\
\text { 3? days }\end{array}$ & $11 \frac{1}{6}$ days \\
\hline 2 & 9 & 6 A.M., June 16 & $\begin{array}{l}12-30 \text { P.M., June } 18 \\
2 \text { days, } 6 \frac{1}{2} \text { hours }\end{array}$ & $\begin{array}{l}3 \text { p.M., June } 20 \\
2 \text { days, } 2 \frac{1}{2} \text { hrs. }\end{array}$ & $\begin{array}{l}4 \text { P.M. June } 22 \\
2 \text { days, } 1 \text { hour }\end{array}$ & $\begin{array}{l}7 \text { A.M.,July } 1^{2} \\
8 \text { dys., } 15 \text { hrs. }\end{array}$ & 15 dys., 1 hr. ${ }^{3}$ \\
\hline
\end{tabular}

Additional records of the actual length of the combined larval instars made in the first two weeks in June, ranged from 16 days, 5 hours to 17 days, 9 hours, the records obtained from but three larvae.

Time in soil previous to pupation. Two records of this give 2 days, 16 hours as the time spent by the larva in the soil previous to pupation. This, of course, varies much with the individual, and we are inclined to think the period somewhat longer on an average.

Eating of eggs in confinement by starved larvae. Whenever egg-masses were brought in from the field and confined in the laboratory, the young larvae finding no food after hatching, would invariably turn their attention to the yet unhatched eggs in the mass, and commence to feed on them. We have seen the entire mass thus destroyed by one or two prematurely hatched larvae.

\section{The Pupa.}

Description. Length, $9.20 \mathrm{~mm}$., average; greatest width, $6.40 \mathrm{~mm} ., 1 \mathrm{st}$ abdominal segment. Broadly ovate, angular, convex above, straight or slightly concaved below; naked. Color orange yellow, abdomen, wings, and legs orange, the median line of abdomen deeper orange; setae brownish; eyes change from pale to crimson and then, after 36 to 48 hours, to orange, with discal surfaces dusky; prothoracic tubercles black; a broad dusky line on dorso-lateral aspect of segments 2 to 5 of abdomen, not contiguous to the spiracles; spiracles black; tip of cremaster black.

Antennae inserted so that at least one-third, the whole of the basal third, is visible from ventral aspect, and from dorsal aspect, its apical third; they cross the base of the eyes and proceeding caudo-laterad (ventral aspect), go beneath the femora of the first and intermediate pairs of legs, where they are almost hidden; their tips reach to the knees of the intermediate legs. Articulation distinct.

Elytra large and rather conspicuous, their basal half plainly visible from ventral aspect, and from dorsal aspect, a longitudinal half of their base is visible. They

\footnotetext{
1 Duplicated in the field.

2 Actual pupation.

3 Actual length of the combined instars, including time in soil previous to pupation.
} 
extend caudo-laterad and then ventrad, between the intermediate and posterior legs. Their tips are opposite to the penultimate tarsal joint of posterior legs. The antennae reach to about their middle and are applied to them.

Stigmata of prothorax visible from ventral aspect; ovate. Those of abdomen visible from dorsal aspect, smaller and rounded oval, those of the first abdominal segment partially concealed.

Setae generally absent, except as mentioned in following; irregular, of medium size, and generally originating from distinct tubercles or papillae.

From dorsal aspect.- Head entirely concealed by prothorax, the latter visible for caudal two-thirds. The knees and tips of the femora of the first and intermediate legs project side by side, from the center of their respective segments; the knees of the first pair of legs are slightly caudad of the insertion of the elytra; those of the intermediate pair are slightly cephalad of the center of the elytra, and are advanced farther laterad; more of the femur of the first pair of legs is visible. The knees of the third pair of legs project from beneath the elytra at the third abdominal segment; the knee alone is visible. The elytra are visible for at least their basal three-fourths. Other appendages not visible. The cremaster visible for its entire length.

Prothorax semicircular in outline, the cephalic edge slightly concave, the lateral edges truncate, the caudal edge curved, and convex at median line; surface convex, with a thin median furrow. About one-third wider than long. In the disk, on each side of and along the median line, the pronotum bears about 13 to 15 rather conspicuous setae arising from small black tubercles; and the entire margins bear many setae, which are inclined to be grouped at the angles. At the dorso-lateral aspect, there is also a group of less conspicuous setae, of 5 or 6 .

Mesothorax as wide as the prothorax, but nearly one-third shorter; nearly three times wider than long. The scutellum regularly peltate, convex, transversely striate, naked. Devoid of setae.

Metathorax slightly wider than prothorax, and about twice longer than mesothorax; with a deep median furrow. Surface glabrous. The thorax about equals the abdomen in length; the segmentation is not distinct.

Abdomen with greatest transverse diameter in the third segment. It tapers but slightly cephalad, but rather abruptly caudad, after the 5th segment, reaching a point in the cremaster. Setae are borne on the caudal margins of the segments, few mesad, numerous laterad, and thick near the spiracles. Segmentation distinct. Seen from lateral aspect, segments 1 to 6 are ridged the ridge cushion-like, and with a deep impression in the disk. Cremaster fleshy, turned dorsad.

Ventral view.- Head semicircular, with a thin median furrow, the tips of the mandibles reaching a point opposite the insertion of the first pair of legs; front 
impressed, with long scattered setae which are not present on the vertex, except laterally. Surface of the eye punctate. The large distal joint of the maxillary palpi is visible, and also the tips of the distal joint of the labial palpi. Each mandible bears at its extremity an acutely conical process, fleshy like a nipple. The maxillary palpi reach the tarsi of the first pair of legs.

Legs compact, the first and intermediate pairs with their femora contiguous. The tarsi of the first pair are applied to the base of the tarsi of the intermediate pair. The tarsi of the posterior pair project from beneath the elytra; the tips of the tarsi of the intermediate pair, which run parallel to the elytra, are applied to the tarsi of the posterior pair. Setae on legs sparse, mostly on knees and tarsi. Ventum of abdomen mostly concealed, a portion of the disk visible.

External development. There are no marked color changes in the pupa during the period just previous to exclusion to the adult. Following pupation, the colors are brighter, and the markings more or less faded, but this is not particularly striking.

\section{Duration of Instar.}

1. Actual Duration. The table which follows gives the actual length of the pupal instar, obtained by allowing larvae to pupate in vials without soil; in three cases, records were obtained by observations on larvae which had pupated at the sides of glass jars filled with soil, and these in nowise differed from the other records, ranging from six to eight days. The actual pupal instar and the time spent in the soil are very different in duration, and hence should be considered apart.

Table IV. Actual Pupal Instars.

\begin{tabular}{|c|c|c|c|c|}
\hline & & & & \\
\hline No. & Pupated & Excluded & days & hrs. \\
\hline 1. & 5 P. M., May 25th. & 6 A. M., June 1st. & 5 & 13. \\
\hline 2. & 6 P. M., May 26th. & 7 A. M., June 1st. & 5 & 14. \\
\hline 3. & 10 A. M., June 10th. & 4 P. M., June 16th. & 6 & 6. \\
\hline 4. & 10 A. M., June 10th. & Noon, June 18th. & 8 & 2. \\
\hline 5. & 7 P. M., June 18th. & 2 P. M., June 25th. & 6 & 19. \\
\hline 6. & 11 P. M., June 19th. & Noon, June 23rd. & 3 & 13. \\
\hline 7. & 11 P. M., June 19th. & 11 A. M., June 25th. & 5 & 12. \\
\hline 8. & Noon, July 4th. & 10 A. M., July 9th. & 4 & 22. \\
\hline & & Sums. & 46 & 5 \\
\hline & & Average. & 5 & 19 \\
\hline
\end{tabular}

2. Length of time in Soil. Records of this are tabulated, for convenience of comparison with the table just presented. 
Table V. Actual Time Passed in Soil.

\begin{tabular}{|c|c|c|c|c|}
\hline \multirow{2}{*}{ No. } & \multirow[b]{2}{*}{ Entered soil for pupation. } & \multirow[b]{2}{*}{ Emerged. } & \multicolumn{2}{|c|}{ Length; } \\
\hline & & & days & hours. \\
\hline 1. & 10 P. M., May 22nd. & 7 A. M., June 2nd. & 10 & 9. \\
\hline 2. & 10 P. M., May 22nd. & 6 A. M., June 2nd. & 10 & 8. \\
\hline 3. & 10 P. M., May 22nd. & 6 A. M., June 2nd & 10 & 8. \\
\hline 4. & 10 P. M., May 22nd. & 3 P. M., June 3d. & 11 & 17. \\
\hline 5. & 8.30 P. M., June 8th & 8 P. M., June 23d. & 14 & $23 \frac{1}{2}$. \\
\hline 6. & 3 P. M., June 11th. & 5 P. M., June 21st. & 10 & 2. \\
\hline 7. & 2 P. M., June 11th. & 9 A. M., June 23d. & 11 & 19. \\
\hline 8. & 5 P. M., June 11th. & 11 A. M., June 22nd. & 10 & 18. \\
\hline 9 . & Noon, June 12th. & 9 A. M., June 23d. & 10 & 21. \\
\hline 10. & P. M., June 11th. & P. M., June 22nd. & 11 & \\
\hline 11. & 4 P. M., June 11th. & Noon, June 22nd. & 10 & 20. \\
\hline 12. & 3 P. M., June 11th. & 10 A. M., June 22nd. & 10 & 19. \\
\hline \multirow[t]{3}{*}{13.} & 2 P. M., June 11th. & 7 A. M., June 24th. & 12 & 19. \\
\hline & & Sums. & 146 & $15 \frac{1}{2}$ \\
\hline & & Average. & 11 & 7 \\
\hline
\end{tabular}

Length of time in soil after eclosion. Two records obtained, give this period as 3 days, 12 hours, and 4 days, 8 hours respectively. By comparing these with the tables in foregoing, they are apparently about correct, the average being about three and a half days.

\section{The Adult.}

Changes in color following eclosion. The changes in coloration undergone by the adult immediately following eclosion, have already been amply described and figured (Tower, 1903), so that no mention of them will be made here.

Length of life in confinement. We have but a single record of this, for a pair of adults captured in copula, 5 P. M., May 20th, and at once confined with food. The male died on June first, having lived 12 days. The female lived until June 7th, or 18 days. As already intimated, we may expect a much longer length of life than this, as both adults were probably some days old when captured.

Copulation and oviposition. The female of this pair deposited 525 eggs from May 21 to June 5th, in masses ranging from 9 to 53 eggs each, and with an average of 29.1 eggs to the mass. The daily rate of deposition was about the same as the average number of eggs per mass. Thus she averaged daily a mass of 29.1 eggs.

During the period of confinement, the pair were observed in copula no less than eleven times, or nearly once daily. On May 20th, they were observed to mate three 
times, and twice on the day following. Then again on May 23rd, and then once daily from May 26th to May 30th, inclusive. The act is normal for the Coleoptera.

Length of life cycle. The lengths of the different stages have already been tabulated. Taking the averages from these and combining them we get the average length of the life cycle, as follows:-

Length of the egg stage -

Length combined larval instars -

Length time in soil -

Average length of life cycle,
4 days, 23 hours

11 days, 6 hours.

11 days, 7 hours.

28 days.

Number of Generations in Georgia. Unfortunately we were unable to gather any definite data bearing on this, but our observations lead us to believe that there are at least three full generations of this insect in this locality of Georgia. This statement is made with qualification.

Natural enemies. During late May, an adult of Sinea diadema Fabricius was captured with a larva of instar III impaled on its beak. The body of the larva was partly collapsed. In confinement, this same individual Sinea destroyed several other larvae in different instars. We are indebted to Mr. Otto Heidemann, United States National Museum, for the determination of this insect.

No true insect parasites were met with.

\section{LITERATURE REFERRED TO.}

1903. Tower, W. L. The development of the colors and color patterns of Coleoptera, etc. Decennial publications, University of Chicago, X, 40 pp., 3 pls.

These notes are published through the kindness of Dr. L. O. Howard, chief of the Bureau of Entomology, U. S. Department of Agriculture.

\section{PODISMA AUSTRALIS NOM. NOV.}

Strict rules of nomenclature seem to require a different name for the species described (Psyche, xiii, p. 120, 1906) as Podisma scudderi, in consequence of the fact that Melanoplus scudderi was once referred to this genus (Walker, Cat. Derm. Salt. Brit. Mus., iv, 718).

A. P. Morse. 

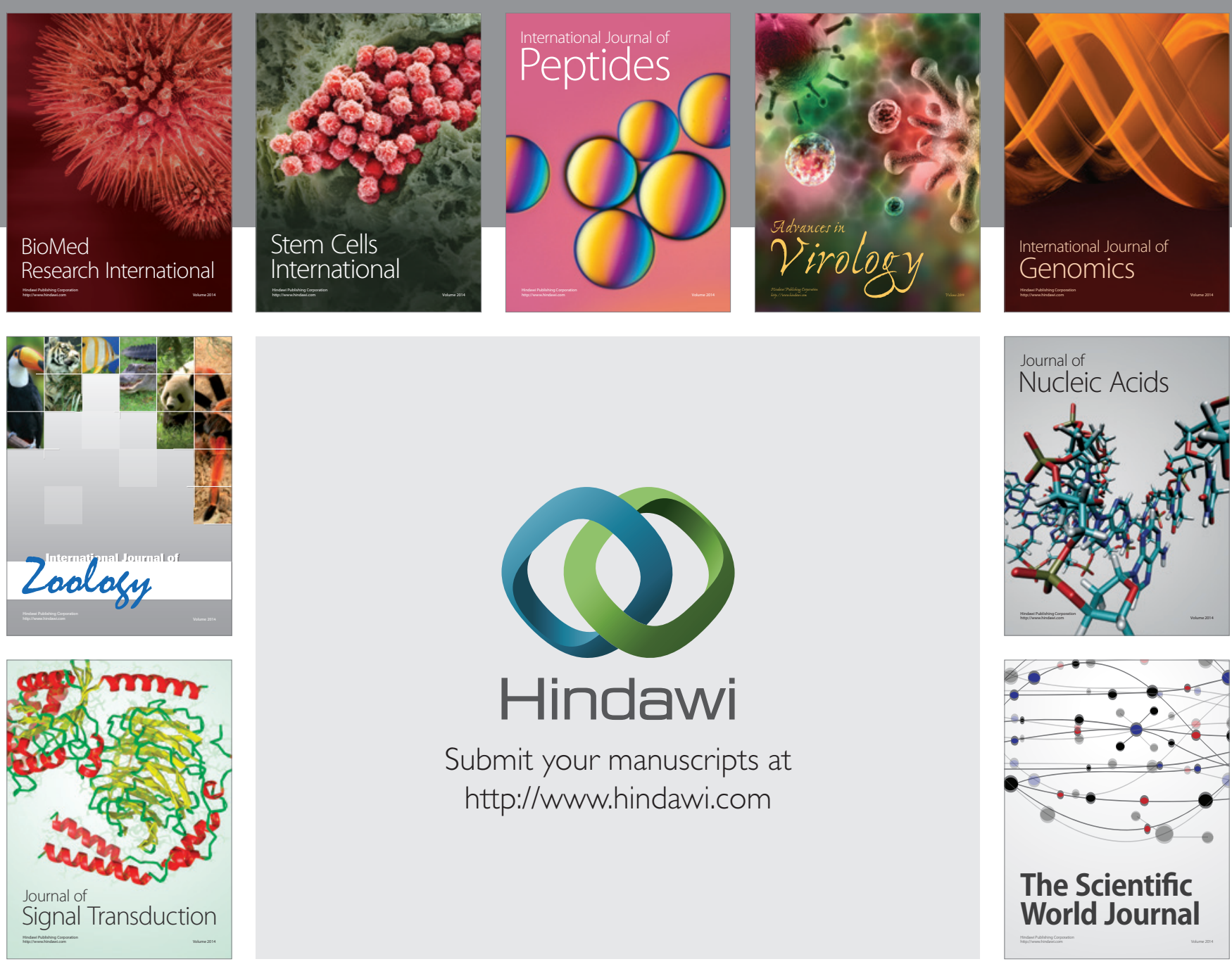

Submit your manuscripts at

http://www.hindawi.com
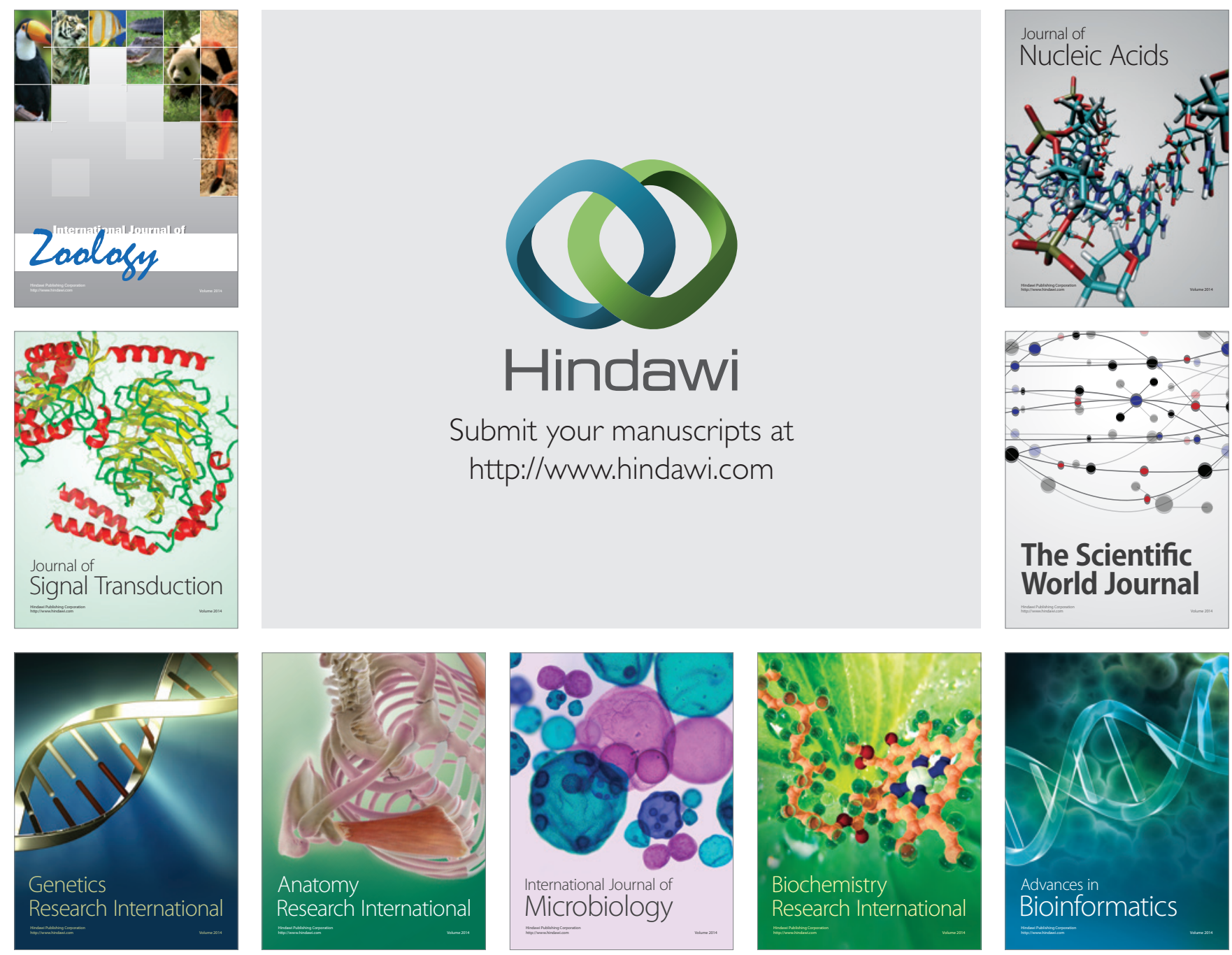

The Scientific World Journal
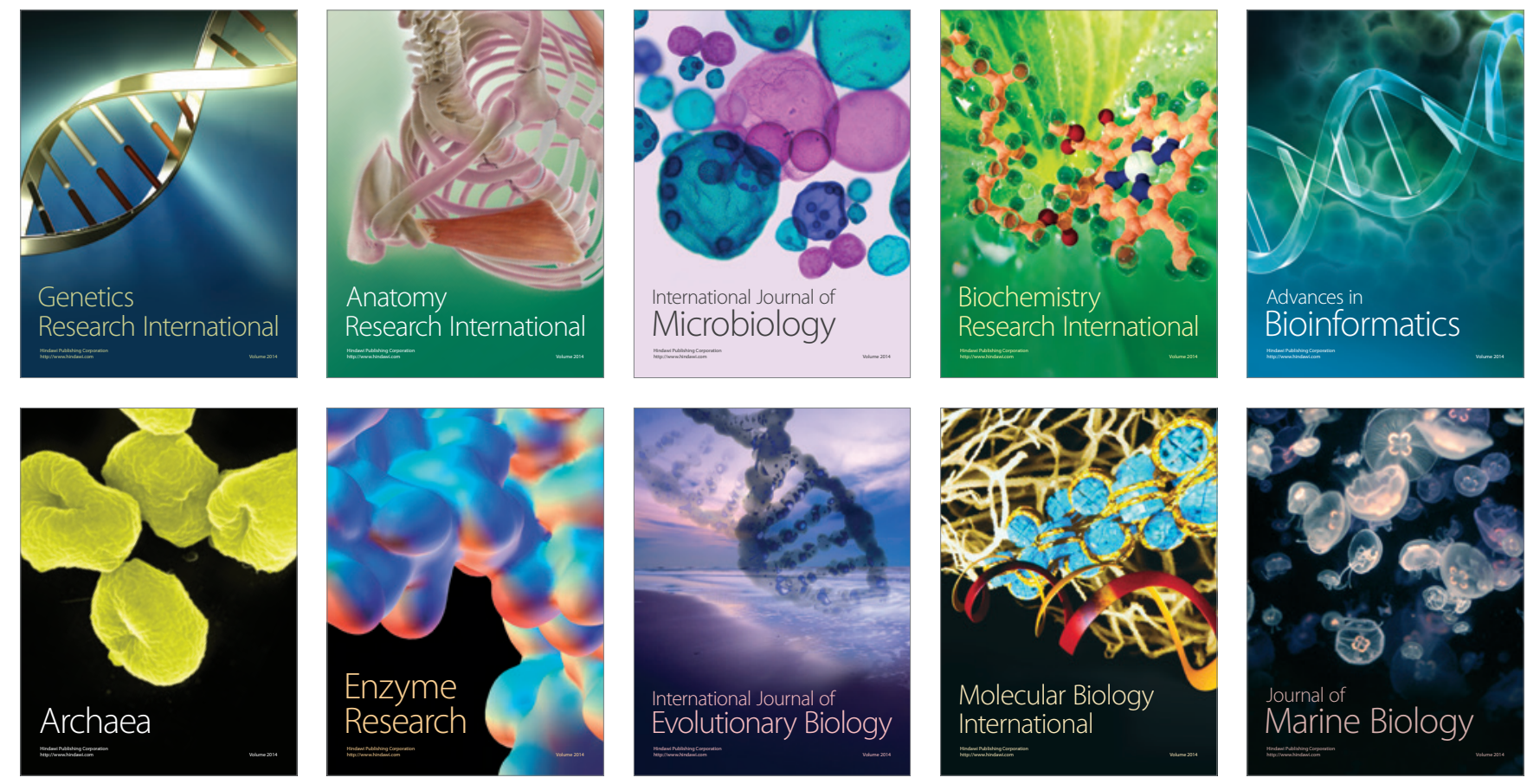